\title{
SUPPORTING FIRST NATIONS AND MÉTIS POST-SECONDARY STUDENTS' ACADEMIC PERSISTENCE: INSIGHTS FROM A CANADIAN FIRST NATIONS-AFFILIATED INSTITUTION
}

\author{
TANIA KRISTOFF \\ UNIVERSITY OF SASKATCHEWAN
}

\author{
MICHAEL COTTRELL \\ UNIVERSITY OF SASKATCHEWAN
}

\begin{abstract}
Post-secondary institutions have a critical role to play in addressing the Truth and Reconciliation Commission (TRC) Calls to Action through indigenization strategies (TRC, 2015) but, to date, it has proven challenging. In this study, the research lens was expanded to focus on First Nations-affiliated post-secondary institutions, since these come closest to providing authentic approaches to indigenization. The purpose of this qualitative case study was to explore how social support affects the academic persistence of First Nations and Métis students at a First Nations-affiliated post-secondary institution. The findings revealed that administrative and pedagogical practices, consistent with Indigenous ontologies, enabled students to respond to challenges stemming from the generational effects of colonization, and promoted individual and familial advancement, cultural growth and identity formation, community development, and Indigenous sovereignty. It is concluded that mainstream institutions can benefit from the findings as First Nations-affiliated post-secondary institutions provide valuable understandings of potential transformations toward indigenization.

Keywords: culturally responsive support, First Nations and Métis post-secondary students, indigenization, academic persistence, First Nations-affiliated post-secondary institutions
\end{abstract}

\section{Résumé}

Les établissements postsecondaires jouent un rôle déterminant pour répondre aux appels à l'action de la Commission de vérité et réconciliation (CVR) par des stratégies d'autochtonisation (CVR, 2015), mais jusqu'ici, l'effort s'est avéré difficile. Dans la présente étude, nous braquons notre objectif sur les établissements postsecondaires affiliés aux Premières Nations, car ceux-ci se rapprochent le plus d'une démarche authentique d'autochtonisation. Notre étude de cas examine la manière dont le soutien social influence la persévérance des étudiant.e.s autochtones et métis.ses dans un établissement postsecondaire affilié aux Premières Nations. Les résultats démontrent que des pratiques administratives et pédagogiques conformes aux ontologies autochtones permettent de relever les défis générationnels associés à la colonisation et de promouvoir le progrès individuel et familial, le développement culturel, la formation de l'identité, le développement des communautés et la souveraineté autochtone. Nous concluons que les établissements conventionnels peuvent bénéficier de ces découvertes les établissements postsecondaires affiliés aux Premières Nations assurent une compréhension inestimable des transformations éventuelles vers l'autochtonisation.

Mots-clés : soutien adapté à la culture, étudiant.e.s postsecondaires, Autochtones et Métis, autochtonisation, persévérance scolaire, établissements postsecondaires affiliés aux Premières Nations

\section{Introduction}

Demographic changes accompanied by shifts in public discourse and policy following the Truth and Reconciliation Commission (TRC) Calls to Action have drawn attention to the history of Canadian colonization and the 
urgent need for reconciliation with the country's Indigenous peoples (TRC, 2015). Post-secondary institutions have been identified as having a critical role to play in "righting wrongs and creating the conditions for Indigenous students to succeed" (Davidson \& Jamieson, 2018, para. 4). Here we argue for expanding the research lens beyond the institutional mainstream to focus on First Nations-affiliated post-secondary institutions. Although relatively young in institutional terms and often suffering from resource constraints, these institutions represent attempts to establish Indigenous presence within the post-secondary landscape in order to make post-secondary programming more accessible and responsive to the needs of Indigenous peoples. Since these institutions currently come closest to animating authentic approaches to indigenizing the post-secondary landscape, examining their approaches and practices can substantially deepen understanding of ways in which the necessary and desired transformations of the academy can be achieved.

We employ qualitative intrinsic case study, framed in Tribal Critical Race Theory (TribalCrit) and interpreted through the Family Education Model (FEM), to delineate the range of supports provided to First Nations and Métis students at a First Nations-affiliated post-secondary institution in Western Canada and to explore how these supports impact the academic persistence of those students. The findings revealed that administrative and pedagogical practices, consistent with Indigenous ontologies, enabled students to respond to challenges stemming from the generational effects of colonization, and promoted individual and familial advancement, cultural growth and identity formation, community development and Indigenous sovereignty. The implications of these findings for the indigenization of post-secondary institutions, including mainstream universities, are then considered.

\section{Relevant Literature}

\section{Canadian Indigenous Students}

While the number of Indigenous peoples earning undergraduate degrees has consistently increased over time, non-Indigenous Canadians are attaining degrees at an exceeding rate. From 1981 to 2016, Indigenous peoples saw an $8.9 \%$ increase in undergraduate degree attainment, yet the post-secondary education (PSE) gap in undergraduate completion rates between Indigenous and non-Indigenous students has widened from $6.1 \%$ to $17.6 \%$ (Statistics Canada, 2013, 2018). As a consequence, nearly $30 \%$ of non-Indigenous Canadians aged 25 to 64 have university degrees, compared with just over $10 \%$ of Indigenous peoples in the same age group (Davidson \& Jamieson, 2018). In the best-case scenario, progress will stagnate, and at worst, the gap will continue to widen as more non-Indigenous people complete undergraduate degrees (Gordon \& White, 2014).

Explanations for this widening PSE gap are multifaceted, with social and economic challenges stemming from the generational effects of colonization being especially problematic (Timmons \& Stoicheff, 2016). Indigenous peoples are amongst the poorest in Canada and funding for Indigenous post-secondary students is often insufficient, inhibiting them from attending PSE and hampering their prospects of completion. Métis and non-Status Indian post-secondary students are ineligible for federal funding through the Post-secondary Student Support Program (PSSSP). Still, the PSSSP lacks the capacity to support all eligible Status Indian and Inuit students (Assembly of First Nations, 2011). Consequently, many Indigenous learners rely on alternate forms of funding such as the Canada Student Loans Program, bursaries and grants, or employment income, which are also often insufficient (Bathish et al., 2017; Bingham et al., 2014).

Socially, Indigenous students are more likely to distrust educational institutions as a result of the generational effects of colonization. Residential schools suppressed Indigenous culture, tradition, and language, hindered coping strategies, and created enduring traumas among those who attended and subsequent generations. Consequently, Indigenous post-secondary students are more likely to have higher risks of mental distress and trauma, poorer self-concept, cultural discontinuity, and are less prepared academically as a result of accumulated multi-generational education deficits (Bombay et al., 2014; Dionne \& Nixon, 2014). These challenges are more evident within the competitive environment of PSE, where Indigenous post-secondary students express significant levels of personal stress and trauma contributing to lower motivation, increased feelings of inadequacy, and lower rates of persistence (Brade et al., 2003; Hardes, 2006).

Families and communities provide significant sup- 
port for many Indigenous students through bonds of affection, childcare, cultural teachings, and motivation (Bingham et al., 2014). Indigenous post-secondary students, who frequently have to relocate to attend post-secondary education, often lose these critical familial and community supports. The resulting isolation is compounded if they encounter staff or faculty members who demonstrate a lack of concern for Indigenous cultures or portray Indigenous peoples inaccurately (Bailey, 2016; Clarke et al., 2014). The lack of familial and community support, coupled with institutional insensitivity to Indigenous cultures and history, often further marginalizes and alienates Indigenous students (Bailey, 2016; Clarke et al., 2014; Indspire, 2018; Restoule et al., 2013). It is crucial to acknowledge the challenges that result from socio-economic marginalization, the generational effects of colonization, geographic dislocation, and cultural differences, as these challenges continue to significantly constrain Indigenous students' success at the post-secondary level.

\section{The Approach of Post-Secondary Institutions}

Over the last two decades, the literature on supporting Indigenous students in post-secondary education has increased dramatically as indigenization and reconciliation become increasingly important warrants for post-secondary institutions (Gaudry \& Lorenz, 2018; TRC, 2015; Universities Canada, 2015). Most institutions have focused on some aspects of Indigenous inclusion and improving access, with a strong focus on the provision of support. House (1981) has identified four types of social support: emotional, instrumental, informational, and appraisal, which can be dependent on or independent of one another. These types of social supports are assumed to be applicable when used to promote academic persistence in Indigenous post-secondary students attending mainstream institutions.

Emotional support has been described as those supportive acts that display empathy, love, trust, and concern (House, 1981). Staff and faculty members who displayed an authentic interest fostered relationships and helped Indigenous students build confidence, selfworth, and a sense of belonging (Embleton, 2012; Gallop \& Bastien, 2016; Guillory \& Wolverton, 2008; Ragoonaden \& Mueller, 2017). Further, it has been demonstrated that empathy and concern, shown by peers, family, and community members, motivated Indigenous students to overcome challenges and grow academically (Lundberg, 2014; Tachine et al., 2017). Indigenous students who received emotional support were able to build relationships and create a network of allies who supported their persistence (Guillory \& Wolverton, 2008).

Instrumental support in the post-secondary setting encompasses specific tangible resources that help students reach a particular outcome or goal (Savitz-Romer et al., 2009). In mainstream institutions, designated Indigenous student centres provide substantial resources for Indigenous students (Embleton, 2012; Hinds, 2014; Guillory \& Wolverton, 2008). For the most part, Indigenous student centres house academic, personal, social, and cultural resources to improve academic persistence. Several studies have demonstrated that Indigenous student centres provide sufficient instrumental support; however, these Indigenous student centres had frequently evolved into communities where Indigenous students felt a sense of belonging and acceptance, which in turn enhanced their persistence (Hinds, 2014; Guillory \& Wolverton, 2008; Smith \& Varghese, 2016).

In addition to receiving emotional and instrumental support, informational support is vital. Savitz-Romer et al. (2009) asserted that receiving advice, knowledge, and guidance can help students meet their academic and personal goals. Accordingly, respectful adoption of Indigenous knowledge, values, and teaching practices into post-secondary courses subsequently increases academic persistence among Indigenous students (Embleton, 2012; Ragoonaden \& Mueller, 2017). Embleton (2012) found that the use of talking circles, experiential learning experiences, and personal stories created supportive and empowering environments for Indigenous students, motivating them to persist in their educational goals. Moreover, Ragoonaden and Mueller (2017) incorporated Indigenous cultural characteristics, experiences, and perspectives into an introductory undergraduate course and found that it supported the connection between Indigenous students, peers, staff, and faculty members. This connection was pivotal to the sense of community and relationships that followed, which reduced feelings of isolation and improved academic persistence (Ragoonaden \& Mueller, 2017).

Mentoring opportunities and constructive feedback are further acknowledged as important appraisal support for Indigenous post-secondary students. Research suggests that Indigenous students who participate in 
mentorship programs create relationships with peers and faculty and formulate a sense of acceptance within the institution, which can improve academic persistence (Archibald et al., 2010; Rawana et al., 2015). Furthermore, faculty members who provide clear expectations and constructive feedback empower Indigenous students to remain in their undergraduate programs of study; conversely, "unclear instructor expectations could further marginalize many of these Aboriginal students by increasing their feelings of self-doubt, inadequacy and overall alienation" (Gallop \& Bastien, 2016, p. 217).

The research literature on the social supports used to promote academic persistence among Indigenous post-secondary students appears to be largely based on mainstream institutions (Gaudry \& Lorenz, 2018). Little Canadian-based research has explored the provision of social support at Indigenous-affiliated institutions or examined connections between those social supports and the academic persistence of Indigenous students at Indigenous-affiliated institutions. This is surprising given that these institutions exist to enable Indigenous peoples to "claim postsecondary education as Indigenous space" (Windchief \& Joseph, 2015, p. 267) by reimagining and reworking post-secondary spaces to "make them accessible to and have the ability to be in relationship with Indigenous communities" (Calderón, 2019, p. 1). To address this gap, the current inquiry aimed to understand how social support affects the academic persistence of First Nations and Métis students at a First Nations-affiliated post-secondary institution. The study was informed by the following research questions:

1. What challenges do First Nations and Métis post-secondary students face at the First Nations-affiliated institution?

2. What is the nature of social support provided to First Nations and Métis students attending the First Nations-affiliated institution?

3. How is social support delivered to First Nations and Métis post-secondary students attending the First Nations-affiliated institution?

4. What effect does social support have on the academic persistence of First Nations and Métis post-secondary students attending the First Nations-affiliated institution?

\section{Theoretical Approach}

The current body of literature on social support and the academic persistence of Indigenous students in post-secondary contexts offers a variety of different theoretical approaches to frame the study and guide data analysis. This study draws upon two approaches; TribalCrit is used to frame the study and the FEM is used to guide data analysis.

The first approach emerges from the TribalCrit, which is an offshoot of Critical Race Theory and Critical Legal Studies. TribalCrit was developed by Brayboy (2005) as a framework to understand the complex experiences of Indigenous peoples in education, acknowledging their unique liminal position as legal/political and racialized beings and stressing the ongoing nature of colonization and disadvantage. Further, TribalCrit offers ways to reconceptualize post-secondary educational spaces so that they better serve Indigenous communities and individuals (Calderón, 2019). This approach "centers both the challenges faced by Indigenous peoples within current educational contexts and highlights the importance of Indigenous cultures, indeed futurities, as central to this work" (p. 2). Although there are nine recognized tenets of the TribalCrit, tenet five was central to framing for this study. The fifth tenet emphasizes that culture, knowledge, and power takes on new significance when examined through an Indigenous lens (Brayboy, 2005). This study examines how First Nation and Métis students make meanings of the supports provided at a First Nations-affiliated institution. TribalCrit's fifth tenet provides that the Indigenous lens used within the First Nations-affiliated institution will influence the perceptions and experiences of First Nations and Métis-identifying students.

This study uses the FEM developed by HeavyRunner and DeCelles (2002) to guide data analysis. HeavyRunner and DeCelles's model was selected because it is an Indigenous-based persistence model, grounded in Indigenous worldview and designed to understand the nature of attrition among Indigenous post-secondary students. FEM is founded on the premise that conventional post-secondary social supports often do not address the complex challenges faced by many Indigenous students (HeavyRunner \& DeCelles, 2002). Hence, institutions must go beyond conventional support systems and work to incorporate Indigenous cultural values, establishing a sense of family as a means of strengthening academic 
persistence in Indigenous students. In particular, understanding an institution's appreciation of the importance of extended family, traditional knowledge, and cultural practices will reveal that institution's knowledge of, and intentions toward, its Indigenous students. Consequently, the model developed by HeavyRunner and DeCelles (2002) offers three presumptions to support academic persistence in Indigenous students.

HeavyRunner and DeCelles's (2002) first presumption in support of Indigenous students' academic persistence identifies that cultural identity cannot be separated from academics and that integration of cultural values are a necessary precursor to academic persistence. In particular, their research shows that supports and services that are guided by traditional knowledge, values, and practices bring forth persistence, while failing to acknowledge culture leads to ineffective academic outcomes. Fostering respect, generosity, and cooperation and incorporating Indigenous philosophy are a few strategies used to support cultural identity and academic persistence (HeavyRunner \& DeCelles, 2002).

In the second presumption, HeavyRunner and DeCelles (2002) acknowledged that the extended family, often integral to meeting holistic needs, plays a significant role in the lives of most Indigenous peoples. Indigenous students who are separated from their extended family are more likely to lack the social support needed to meet their emotional, mental, and spiritual needs, which then leads to negative academic consequences (Guillory \& Wolverton, 2008). HeavyRunner and DeCelles (2002) noted that engaging students' extended family in campus social and cultural events creates a sense of belonging for both students and their families, and that a sense of family is assumed to form a collective for supporting Indigenous students' academic persistence.

HeavyRunner and DeCelles's (2002) third presumption recognizes that post-secondary institutions must act as liaisons for Indigenous students, stating that in addition to conventional support, faculty and staff members need to act as the students' extended family and replicate the way the extended family operates, through building respectful relationships, providing culturally-based knowledge, being flexible and responsive, and affirming strengths and abilities. According to their findings, a family-centred approach strengthens academic persistence in Indigenous students and empowers them toward personal and national autonomy (HeavyRunner
\& DeCelles, 2002).

The presumptions from the FEM were used to understand the perspectives of First Nations and Métis students attending a First Nations-affiliated institution. It was found that First Nation and Métis students acted and reacted to social supports based on their experiences. The students associated their experiences with effects on their academic persistence, which allowed for a clear understanding of perspective.

\section{Methodology}

\section{Research Design}

A qualitative intrinsic case study approach was employed to explore how social support affects the academic persistence of First Nations and Métis students at a First Nations-affiliated university. According to Stake (1995), an intrinsic case study draws researchers toward understanding what makes a case worth investigating. The case selected for this study, First Nations University of Canada (FNUniv), Northern campus, is a First Nations-affiliated institution. Barnhardt (1991) asserted that affiliated institutions contribute to the educational aspirations and needs of Indigenous students, but cannot operate as independent institutions, and therefore are required to establish a contractual relationship with a mainstream institution. As an affiliated institution, FNUniv administers educational services for Indigenous and non-Indigenous students under the academic and administrative authority of the University of Regina. The affiliated designation not only allows the FNUniv to support Indigenous students through culturally responsive administration, curriculum, research, and student support, but also gives the FNUniv increased credibility granted by its association with the University of Regina.

FNUniv is a First Nations-controlled institution that specializes in Indigenous knowledge and provides education in a culturally responsive environment, while building capacity in Indigenous individuals, communities, and nations (FNUniv, n.d.). Although many mainstream institutions offer Indigenous programs based on the needs of Indigenous students within a particular geographical location, or as a response to an increased population of Indigenous students within a current department, there is limited evidence of institutions fully 
integrating Indigenous knowledge into curricula and providing resources to meet the needs and values of Indigenous students. Acknowledging the difference between institutions, this case study offers an opportunity to gain new insights into how social supports affect the academic persistence of First Nations and Métis students at a First Nations-affiliated post-secondary institution.

\section{Case Description and Boundaries}

In case study research it is important to provide detailed information about the case and its boundaries; this allows readers to develop a comprehensive understanding of the phenomenon under investigation (Stake, 1995) and the limits for the inquiry (Lincoln \& Guba, 1985). This case was bounded by geographical and institutional context and the sample population.

\section{Geographical Context}

FNUniv has three campuses throughout Saskatchewan: Regina, Saskatoon, and Prince Albert. The study occurred at the Northern campus located in Prince Albert, Saskatchewan. The city of Prince Albert is the third-largest city in Saskatchewan and is located geographically in the centre of the province. According to Statistics Canada (2016), the city of Prince Albert is home to 35,926 residents, $45.3 \%$ identifying as male and $54.7 \%$ as female, with $63 \%$ of the total population falling within the age range of 15-64. The Indigenous population accounted for $31 \%$ of the total population of Prince Albert, with 8,240 people identifying as First Nations peoples, 6,420 as Métis and 10 peoples as Inuit (Statistics Canada, 2016). It is notable that these population statistics may be skewed, as census data on First Nations, Inuit, and Métis peoples have often not been separated accurately (Smylie et al., 2011).

\section{Institutional Context}

Many of the undergraduate programs offered at FNUniv's Northern campus originated from the requests of First Nations communities and the necessity to sustain and share First Nations culture. The campus actively works toward cultural sustenance and revitalization by incorporating First Nations values into administrative policies, bridging Western and Indigenous knowledge, and using traditional practices in teaching and learning. FNUniv has responded to students' needs by creating environments, academic programs, research opportunities, and supportive services that centre on the sharing of Indigenous knowledge and strengthening cultural traditions. FNUniv uses cultural approaches that focus on students' cultural frames of reference through the incorporation of Indigenous knowledge, values, and traditional teaching practices in a culturally appropriate manner; this approach aims to help students to create sustainable communities and build strong Indigenous nations (Begay, 2016; Cornell \& Kalt, 1998; Gay, 2013). Subsequently, all of FNUniv's undergraduate programs are culturally responsive and integrate Indigenous knowledge, incorporate traditional teaching practices, and use prior experiences to make learning relevant for students.

\section{Sample Population}

As a First Nations-controlled institution, FNUniv's Northern campus has a unique student, staff, and faculty population that is different from typical mainstream post-secondary institutions. At the time of the study, the student enrolment at the Northern campus was 281 students, with 228 students self-identifying as being either of First Nations or Métis descent, and the majority of those students asserting First Nations heritage (Office of the Registrar, 2018). Of this student population, 37 identified as male, two as non-binary, and 189 as female (Office of the Registrar, 2018). Consequently, 67\% of the total student population at the Northern campus was composed of female students who identified as being First Nations or Métis. There were nine tenure-track faculty members in full-time or part-time assignments. Of the nine faculty members, almost half were of First Nations or Métis heritage. Of the 24 staff employees, a greater number were of First Nations descent. At the Northern campus, First Nations and Métis peoples were the majority, and for many, this was a unique opportunity to learn and be taught, counselled, and recognized by other First Nations and Métis peoples within a culturally responsive environment.

As the research involved Indigenous peoples, the ethical guidelines outlined in the Tri-Council Policy Statement Ethical Conduct for Research Involving Humans (TCPS2) were followed (Canadian Institutes of Health Research et al., 2018). This included the establishment of an advisory group consisting of an Elder, a staff member who was a Cree/Métis woman, and a non-Indigenous faculty member from the Northern campus. 


\section{Participants and Recruitment}

Purposeful sampling techniques based on three discrete sample groups were used. Criteria for the first sample group included currently employed full-time, part-time, or sessional FNUniv faculty presently teaching undergraduate Indigenous students. Criteria for the second sample group included FNUniv staff employees currently employed and providing supportive services to undergraduate Indigenous students. Criteria for the third sample group included self-identified FNUniv Indigenous undergraduate students who were currently attending undergraduate courses. Overall, there were approximately 100 students, faculty, and staff members contacted through recruitment strategies. Finally, 24 participants self-selected to participate in the study. These included six faculty members, 11 staff members, and seven students who identified as being of First Nations or Métis heritage.

\section{Data Collection}

Based on consultation with the advisory group, it was determined that field notes and memos, focus group interviews, and face-to-face interviews would be used as the data collection methods. Field notes and memos were used to gain a rich account of the institutional context and to observe social exchanges between participants during the focus group interviews. Four focus group interviews were conducted to elicit the participants' perspectives, insights, and lived experiences, including feelings and opinions on the nature of social support and the ways this affected the academic persistence of First Nations and Métis students. A face-to-face interview was held with a member of each of the sample groups, after the focus group interviews. The purpose of the face-toface interviews was to unpack pertinent experiences, fill in gaps, and confirm or refute emerging ideas that arose from the focus group interviews.

\section{Data Analysis}

Creswell and Poth's (2018) Data Analysis Spiral was followed to complete this within-case analysis and five main analysis procedures were employed. The data was reviewed, and the constant comparative method was used to compare each piece of data against others. After several levels of coding were completed, preliminary re- sults were shared with the advisory group and interview participants, who provided valuable insight on alignment between our interpretations and their experiences and insights. Additional interpretation of the data led to the identification of themes. The themes that emerged from the data were organized into challenge clusters and categories using HeavyRunner and DeCelles's (2002) model. The advisory group reviewed and supported the interpretation. The group appreciated how the findings achieved a balance between institutional strengths and areas for improvement. In addition to using the advisory group for peer review, the strategies of triangulation, thick description, and member-checking were used to ensure qualitative validity and reliability (Patton, 2015).

The following are the four central themes that emerged from data analysis, coupled with illustrative quotes used to reveal the richness of the multiple perspectives based on the lived experiences of the participants. Participants were referenced under pseudonyms to protect their identities and reduce the risks associated with potentially damaging data.

\section{Challenges}

Almost every participant spoke of the persistence of personal-, familial-, social-, and campus-level challenges that negatively impacted First Nations and Métis students' capacity to achieve success. There was a related consensus that many of these challenges stemmed from the generational effects of colonization and related to ongoing marginalization. "Jane," a student participant, expressed that "we're battling the negative messages that we received from our parents and grandparents, community members, who attended residential schools, that we are inferior people." For some students this resulted in feelings of unworthiness and lack of confidence in their academic ability. "Denise," another student participant, shared her self-doubt by saying "when I think about university, my thoughts are, will I be able to do these papers and assignments, and am I going to fit in?" This quote was representative of how most of the student participants viewed the effects of marginalization and colonization.

Once First Nations and Métis students relocated, they were often disconnected from their familial and community supports; some students struggled to adequately care for their families and meet academic demands in an unfamiliar environment. "Francis," a faculty participant, verified that students leave PSE "when the family unit 
breaks apart.... If their babysitter takes off on them, and then they can't find anybody to work with them, they end up quitting and going home." Other participants revealed that these challenges were exacerbated by restricted funding, often causing profound financial distress to the point where some students were unable to meet the basic needs of food, shelter, and childcare. "Sidney," another faculty participant, said "we have students that are couch-surfing just trying to get through the term. Like, they've lost their house, and their kids had to move back home so that somebody could watch them and so they're living from couch to couch."

The perception that FNUniv's Northern campus, as a First Nations-affiliated institution, was less academically credible than other mainstream institutions was a key academic tension for some of the participants. Sidney shared that "as an Indigenous institution, we're not seen as credible...there is a perception of lack of credibility." Some non-Indigenous students or students with a Western perspective perceived FNUniv's Northern campus as offering poorer quality and less academically rigorous programs compared to other mainstream institutions. This caused some First Nations and Métis students to question the value of their education. Illustrative of this point is a comment provided by Sidney:

I know I'm fighting against people's opinions that our institution doesn't have the same rigour as other institutions. And so I need to make sure my students are not only meeting the minimum, they're meeting the maximum and then they're going $10 \%$ over the maximum. Because they're going to be questioned about what they know and if they're not doing it to $110 \%$, then they are again falling into that perspective that they don't know what they're doing.

\section{Nature of Social Support}

Because of the challenges, participants pointed to the critical importance of social support derived from a variety of sources including peers, families, community members, and the staff and faculty at the Northern campus. Participants expressed that having the ability to be with other First Nations and Métis students who had similar life experiences, including occupying a unique liminal identity that combined racial/cultural and legal/ political dimensions shaped by historic and ongoing oppression, created a sense of safety and community and fostered family-like peer networks where students acted as substitute family members for each other. The following comment by "Kallie," a student participant, is representative of the unique peer support evident at the Northern campus:

My biggest support for sure would definitely be the students. Just the closeness that you just gain with everybody whether you have one class with them, or you meet them in the hallway. Everybody wants to say hi, and everybody has each other's back. I don't mind helping somebody else if I'm not in the same class. If

I can give advice or even spell-check an essay.

Other participants recognized that students' families and communities provided important assistance with safe and reliable childcare, finances, and emotional and psychological support, which bolstered students' sense of purpose and motivation. "Rita," a faculty participant, noted, "the ability to go back to the community is really important for our students...just to get grounded again and remind them why they're doing this."

Additionally, many participants stressed that the integration of students' families into the campus setting provided critical support by deepening students' engagement and building cultural connections. The ability to bring children on campus and participate in traditional practices acknowledged the value of family as an integral component in the students' educational process and subsequently strengthened connections between First Nations and Métis students, their families, and the Northern campus community. A student participant, "Melanie," confirmed that "the university [FNUniv's Northern campus] was more open [to families on campus], it's more welcoming and my family wants to come back." The integration of family into the campus environment coincided with the presumption of the FEM that the integration of family created a sense belonging and web of support for First Nations and Métis students.

Student participants also established that staff and faculty members provided social support through a variety of conventional services that were delivered using culturally responsive and sustaining approaches. Participants expressed that the immersion of Indigenous practices and values into conventional academic services, and the incorporation of Indigenous worldviews and traditional teaching styles into the curriculum, facilitated student learning. One faculty participant shared how teaching 
with a First Nations worldview focused on sharing practical cultural knowledge that was applicable to students' academic studies and future careers. Rita stated:

Look at teaching, we don't focus on Western theories, we do cover them, but [what] we really cover in our program is what is effective teaching for First Nations kids. How does language and culture affect learning?... They're not just learning for the sake of passing an exam, they're learning something that's going to be really worthwhile and valuable to them.

The integration of First Nations pedagogy built on students' cultural strengths and connected new learning to their personal and professional journeys in an additive manner. Consequently, the FEM presumption that traditional Indigenous cultural values are a necessary precursor to academic persistence, as cultural identity cannot be separated from academics, was supported.

\section{Enabling Social Support}

Participants shared that the various supports described above, especially those provided by staff and faculty members, were facilitated through the creation of close and caring relationships with First Nations and Métis students. Student participants recognized that staff and faculty members went above and beyond their professional obligations and boundaries and were open and available, displayed empathy, provided comfort and counsel, and were always encouraging. Illustrative of this point, Denise shared, "I thought it would be more like coming to jail...[but] you are treated well and respected. They care about you."

The opportunities for First Nations and Métis students to be heard and validated were acknowledged as a type of familial or kinship support that most students lacked due to being displaced from their own families and communities. Staff participant "Donna" stated:

As staff and faculty, we're filling that family role, we're filling the role of the aunties and uncles and the grandmas and the grandpas for them.... It's kind of like an unspoken common knowledge that we're supporting them in that way, as we would if we were family.

"Margo," another staff participant, concurred:

Our students perceive Northern Campus to be one of their home fires, a safe place....and a home away from home. Because what I perceive is that many of our students who come here have left behind their familial and community supports and network.

Participants discussed how faculty and staff members integrated culturally responsive and sustaining approaches throughout the campus environment and consequently developed a sense of place for First Nations and Métis students. Culturally responsive and sustaining approaches incorporated Indigenous knowledge, values, and strengths into daily interactions and within curricula. This conception was corroborated by Rita:

It's not just a culturally inclusive curriculum; it's a culturally inclusive environment where people really care about you and respect you. I think it's evident in our relationships with our students that we teach. I think that they know that we really care about them not just as students, but...as cultural people.

The culturally responsive and sustaining approaches created a supportive environment that was unique to this case institution. Participants acknowledged that exposure to cultural ceremonies and traditional teaching methods was significant to their education and personal lives. Jane shared:

I also know that being here...is about building relationships, but it's also experiential learning, and there are some classes where we're required to go to like to moon ceremonies, to a lake water ceremony, to a sweat lodge ceremony, and then the cultural camp... and those have value and you cannot teach that in a classroom setting, you need to experience it, absolutely.

The sharing of First Nations and Métis knowledge through an Indigenous lens and as part of a larger community-development and nation-building enterprise, accompanied by evidence of respect, cooperation, and fairness, created a level of comfort and acceptance for First Nations and Métis students.

\section{Effects of Social Support on Students' Academic Persistence}

Another major theme that emerged from this study was that social support influenced more than academic ability; it further encouraged personal growth and motivation, built resilience, and helped shape students' identities. 
Several participants confirmed that the social support First Nations and Métis students received from families and communities inspired them to provide a better life for their families and to give back to their communities as part of a nation-building strategy. Margo stated that "their children become the emphasis for moving them forward...and to make a difference," while Rita said that "they want to use their skills and knowledge...to help their communities."

Other participants identified how social support assisted in building resiliency by helping First Nations and Métis students define their sense of purpose and recognize their abilities. Sidney said:

It wasn't just achieving the certificate at the end...that defined success, but the students identifying what their goals were, what their limitations were, what their vision was. And once they tapped into that, then came the persistence.

When social support highlighted students' positive attributes, students acknowledged their sense of purpose and gained confidence in their abilities to meet their own goals.

Participants discussed how social support and engagement in culturally responsive and sustaining approaches shaped students' First Nations and Métis identities. Data highlighted that First Nations and Métis post-secondary students attending Northern campus were diverse in their socioeconomic backgrounds, cultures, linguistics, lifestyles, and beliefs; consequently, they were not a uniform group with a single identity. The exposure to traditional knowledge, Elders, languages, cultural practices, and ceremonies, through culturally responsive and sustaining social support, provided students with opportunities to learn who they were through an exploration of the four elements of life: physical, mental, emotional, and spiritual. Jane said:

It's [social support] connecting me to my identity and my home and who I am, that foundation. The foundation that was there that I didn't recognize or the foundation that wasn't there at all that I'm building on.

Sustained and culturally responsive social support elicited a sense of pride in First Nations and Métis students and shaped more fluid, nuanced, and robust cultural, professional, and personal identities.

\section{Discussion}

This study sought to describe the effects of social support on the academic persistence of First Nations and Métis students attending a First Nations-affiliated post-secondary institution. In some respects, the results in this study are consistent with prior literature. For example, the findings that suggest First Nations and Métis students face a variety of persistent challenges and that culturally responsive social support can improve academic persistence in First Nations and Métis students are consistent with prior research (Embleton, 2012; Ragoonaden \& Mueller, 2017; Timmons \& Stoicheff, 2016). A noteworthy finding in this study is that integration of family and family-like support and the use of culturally responsive and sustaining approaches developed a sense of self and community among First Nations and Métis students.

Many participants in the study stressed the value of integrating family and family-like support for First Nations and Métis students at the Northern campus. They expressed similar views to those described by HeavyRunner and DeCelles (2002), maintaining that educational institutions that replicate the functions traditionally held by family members and incorporate family into the students' academic life can more holistically support Indigenous students, thereby enhancing prospects of academic persistence. The results of this study provide adequate support for the integration of family into the campus environment and for engaging staff and faculty members to enact family-like responsibilities as a means of encouraging academic persistence in First Nations and Métis students. Hence, these strategies can be assembled as new factors leading to academic persistence in First Nations and Métis students. However, the results of this study also indicate that staff and faculty members at the Northern campus went above and beyond to engage family and provide family-like support by showing care and compassion, assisting with securing resources, and sharing cultural knowledge and spiritual practices, which required an institutional level of commitment.

The data in this study also revealed that culture was a strong presence, which had an overwhelmingly positive influence on the First Nations and Métis students, staff, and faculty members at the Northern campus. First Nations culture provided the foundation for the mission, curricula, and supportive services at FNUniv, which is 
committed to sharing quality bi-lingual and bi-cultural education to all "Indigenous and non-Indigenous students within a culturally supportive environment" (FNUniv, n.d.). This confirms Battiste's (2002) declaration that "Indigenous knowledge is now seen as an educational remedy that will empower Aboriginal students if applications of their Indigenous knowledge, heritage and language are integrated into the Canadian educational system" ( $p$. 9 ). The curricula were infused with Indigenous history, language, culture, and artistic heritage that supported the use of traditional teaching strategies and served as vehicles for bridging Indigenous knowledge with conventional academic learning. It seemed evident that staff and faculty at FNUniv were providing what several authors (Ladson-Billings, 2014; Paris, 2012; Santamaría \& Santamaría, 2016) described as culturally sustaining practices, an approach defined as having the "explicit goal [of] supporting multilingualism and multi-culturalism in practice and perspective for students and teachers" (Paris, 2012, p. 95). Paris (2012) suggested that such approaches go beyond being responsive or relevant to the cultures of minoritized youth in that they "seek to perpetuate and foster-to sustain-linguistic, literate, and cultural pluralism as part of the democratic project of schooling" (p. 95). Such culturally sustaining practices democratize schools by placing "social justice and equity at the forefront of practice" (Santamaría \& Santamaría, 2016, p. 5), while "supporting both traditional and evolving ways of cultural connectedness for contemporary youth" (McCarty \& Lee, 2014, p. 95).

Although most participants agreed that the integration of culturally responsive and sustaining approaches is useful in promoting academic persistence in First Nations and Métis students, others revealed there is a misconception that culturally responsive and sustaining approaches made for a less rigorous educational experience. Most of the staff and faculty participants said they address this misconception by expecting more from the students. Consequently, staff and faculty members assumed the responsibility to help First Nations and Métis students to excel so that when they graduated, they were viewed as exceeding academic standards and being well prepared for their profession.

Finally, the data revealed that sustained and culturally responsive social support influenced more than the intellectual development of First Nations and Métis students; this type of support imparted a holistic effect that further touched the students' families and their broader Indigenous communities. Culturally responsive social support helped to build First Nations and Métis students' resilience, shape their identity, and create motivation to reciprocate to their families and their larger Indigenous nation. Pidgeon $(2008,2014)$ found that Indigenous students associated academic success with more than intellectual accomplishments. Notably, she found that as some Indigenous students progressed through their academic programs, they grew mentally, emotionally, and culturally in their abilities to achieve their individual goals and aspirations, give back to their families and broader communities, and "maintain their cultural integrity" (Pidgeon, 2008, p. 143). In order to understand the true value of culturally responsive social support, recognition of deeper connections between academic persistence, and the significance of PSE for community revitalization, nation-building, and forging Indigenous sovereignty, is required.

\section{Implications}

In their analysis of current administrative meta-policies across the Canadian PSE landscape, Gaudry and Lorenz (2018) suggest that three distinct visions of indigenization have emerged. Indigenous inclusion aims to increase the number of Indigenous students, faculty, and staff within the Canadian academy. Reconciliation indigenization locates indigenization on common ground between Indigenous and Canadian ideals, creating a new, broader consensus. Decolonial indigenization envisions the wholesale overhaul of the academy so that it is fundamentally transformed by deep engagement with Indigenous peoples, Indigenous intellectuals, and Indigenous knowledge systems (Gaudry \& Lorenz, 2018). This case study thoroughly explored FNUniv's Northern campus and offers rich detail which can provide a valuable contribution to larger conversations about indigenizing PSE in Canada and beyond.

At FNUniv's Northern campus educational spaces are reimagined and reworked so that the needs and interests of First Nations and Métis students and communities are prioritized and advanced. This is done by acknowledging and attending to the material and psychosocial realities of colonization through the provision of holistic supports within a web of family-like connections where culture and ceremony are pervasive. Further, the 
learning environment encompasses both Western and Indigenous ontologies and epistemologies, and nurtures students in an affirming, appreciative, and additive way as individuals and members of families, communities, and nations. This approach corresponds most closely to Gaudry and Lorenz's (2018) conception of decolonizing indigenization. While its merits are obvious in terms of supporting student success, it is also important to acknowledge that it would require a very significant transformation of the mainstream academy in multiple areas, including institutional governance and management systems, curricula and pedagogy, student engagement and support systems, and relationships with external communities (Bopp et al., 2017). This approach to indigenization, which would require institutions to focus on "the lived experiences of Indigenous students, staff, and faculty" (Pidgeon, 2016, p. 87), would likely require embracing greater change than can be made comfortably and easily. But in addition to pursuing an unequivocally moral purpose, the rewards in the form of an enriched post-secondary education for all learners will be commensurate with the effort.

\section{Conclusion}

This study sought to explore connections between the provision of supports and the achievement of academic persistence among First Nations and Métis students at FNUniv's Northern campus. The case study highlighted ongoing disadvantages experienced by Indigenous people currently pursuing PSE and efforts at this First Nations-controlled institution to mediate those disadvantages by claiming PSE as Indigenous space. This was achieved by replicating Indigenous kinship networks to create a family-like web of support for students and their families and by mobilizing Indigenous ontologies, epistemologies, languages, cultures, and ceremonies as sources of knowledge-creation, healing, and identity-formation. Consequently, staff and students at FNUniv's Northern campus saw PSE as not merely a path to individual intellectual and material advancement but also as a crucial part of a larger process of community development and nation-building for assertions of Indigenous sovereignty. This case study contributes new insights and illuminates the effects of culturally responsive supports on the academic persistence of First Nations and Métis students; therefore, we suggest that admin- istrators, faculty, and staff from mainstream institutions have much to learn from the innovative practices and approaches developed by FNUniv's Northern campus as they work to indigenize the mainstream academy for the benefit of all learners.

\section{References}

Archibald, J., Pidgeon, M., \& Hawkey, C. (2010). Aboriginal transitions: Undergraduate to graduate phase 1 final report. Indigenous Education Institute of Canada. http://aboriginallearning.ca/wp-content/ uploads/2015/02/UBC-Aboriginal-Transitions.pdf

Assembly of First Nations. (2011). Fact sheet First Nations post-secondary education. https://www.afn. ca/wp-content/uploads/2018/07/PSE Fact Sheet ENG.pdf

Bailey, K. (2016). Racism within the Canadian university: Indigenous students' experiences. Ethnic and Racial Studies, 39(7), 1261-1279. https://doi.org/10 $.1080 / 01419870.2015 .1081961$

Barnhardt, R. (1991). Higher education in the fourth world. Tribal College: Journal of American Indian Higher Education, 3(2), 11-13. https://tribalcollegejournal.org/higher-education-fourth-world/

Bathish, N., Deshpande, R., Kreps, P., Martin, H., Powless, S., \& Sitarz, U. (2017). Policy paper: Indigenous students. Ontario Undergraduate Student Alliance. https://d3n8a8pro7vhmx.cloudfront.net/ousa/ pages/83/attachments/original/1617981452/Indigenous Students 2017 document.pdf?1617981452

Battiste, M. (2002, October 31). Indigenous knowledge and pedagogy in First Nations education: A literature review with recommendations. Indian and Northern Affairs Canada. https://www.afn.ca/ uploads/files/education/24. 2002 oct marie battiste indigenousknowledgeandpedagogy lit review for_min working group.pdf

Begay, M. (2016, March 9). Importance of culture and education in Indigenous nation-building. SAY Magazine, 72. https://saymag.com/importance-of-culture-and-education-in-indigenous-nation-building/

Bingham, J. L., Adolpho, Q. B., Jackson, A. P., \& Alexitch, L. R. (2014). Indigenous women college 
students' perspectives on college, work and family. Journal of College Student Development, 55(6), 615-632. https://doi.org/10.1353/csd.2014.0055

Bombay, A., Matheson, K., \& Anisman, H. (2014). Appraisals of discriminatory events among adult offspring of Indian residential school survivors: The influences of identity centrality and past perceptions of discrimination. Cultural Diversity and Ethnic Minority Psychology, 20(1), 75-86. https:/l doi.apa.org/doi/10.1037/a0033352

Bopp, M., Brown, L., \& Robb, J. (2017). Reconciliation within the academy: Why is indigenization so difficult? Four Worlds Centre for Development Learning. http://www.fourworlds.ca/pdf downloads/ Reconciliation within the Academy Final.pdf

Brade, C., Duncan, K., \& Sokal, L. (2003). The path to education in a Canadian Aboriginal context. Canadian Journal of Native Education, 27(2), 235-248. https://search.proquest.com/openview/9f832d0cac7fc384230f95d5d5ab3a96/1?pq-origsite=g$\underline{\text { scholar \&cbl }=30037}$

Brayboy, B. M. J. (2005). Toward a tribal critical race theory in education. The Urban Review, 37(5), 425-446. https://doi.org/10.1007/s11256-0050018-y

Calderón, D. (2019). Tribal critical race theory: Origins, applications and implications. Center for Critical Race Studies in Education at UCLA: Research Briefs, 19, 1-3. https://issuu.com/almaiflores/docs/ dc tribalcrit

Canadian Institutes of Health Research, Natural Sciences and Engineering Research Council of Canada, \& Social Science and Humanities Research Council of Canada. (2018). Tri-council policy statement: Ethical conduct for research involving humans. Secretariat on Responsible Conduct of Research. https://ethics.gc.ca/eng/policy-politique tcps2eptc2 2018.html

Clarke, D. A., Kleiman, S., Spanierman, L. B., Isaac, P., \& Poolokasingham, G. (2014). "Do you live in a tepee?": Aboriginal students' experiences with racial microaggressions in Canada. Journal of Diversity in Higher Education, 7(2), 112-125. https://doi.apa. org/doi/10.1037/a0036573
Cornell, S., \& Kalt, J. P. (1998). Sovereignty and nation-building: The development challenge in Indian country today. American Indian Culture and Research Journal, 22(3), 187-214. https://doi.org/ 10.17953/aicr.22.3.Iv45536553vn7j78

Creswell, J. W., \& Poth, C. N. (2018). Qualitative inquiry $\&$ research design: Choosing among five approaches (4th ed.). Sage.

Davidson, P., \& Jamieson, R. (2018, November 19). Advancing reconciliation through post-secondary education. Policy Options. https://policyoptions. irpp.org/magazines/november-2018/advancing-reconciliation-through-post-secondary-education/

Dionne, D., \& Nixon, G. (2014). Moving beyond residential school trauma abuse: A phenomenological hermeneutic analysis. International Journal of Mental Health and Addiction, 12(4), 335-350. https:/l doi.org/10.1007/s11469-013-9457-y

Embleton, K. J. (2012). Factors contributing to their success: Experience of Manitoba Aboriginal students in post-secondary education. [Unpublished master's thesis]. University of Manitoba.

First Nations University of Canada. (n.d.). About us. https://www.fnuniv.ca/about-us/

Gallop, C. J., \& Bastien, N. (2016). Supporting success: Aboriginal students in higher education. Canadian Journal of Higher Education, 46(2), 206-224. https://doi.org/10.47678/cjhe.v46i2.184772

Gaudry, A., \& Lorenz, D. (2018). Indigenization as inclusion, reconciliation, and decolonization: Navigating the different visions for indigenizing the Canadian academy. AlterNative: An International Journal of Indigenous Peoples, 14(3), 218-227. https://doi. org/10.1177\%2F1177180118785382

Gay, G. (2013). Teaching to and through cultural diversity. Curriculum Inquiry, 43(1), 48-70. https://doi. org/10.1111/curi.12002

Gordon, C. E., \& White, J. P. (2014). Indigenous educational attainment in Canada. The International Indigenous Policy Journal, 5(3), Article 6. https:// doi.org/10.18584/iipj.2014.5.3.6

Guillory, R. M., \& Wolverton, M. (2008). It's about family: 
Native American student persistence in higher education. The Journal of Higher Education, 79(1), 58-89. https://www.jstor.org/stable/25144650

Hardes, J. (2006). Retention of Aboriginal students in postsecondary education. Alberta Counsellor, 29(1), 28-33. https://ciel.viu.ca/sites/default/files/ approaches to $a b$ ed in canada.pdf

HeavyRunner, I., \& DeCelles, R. (2002). Family education model: Meeting the student retention challenge. Journal of American Indian Education, 41(2), 29-37. https://www.jstor.org/stable/24398576

Hinds, C. D. (2014). Aboriginal student persistence and success in Ontario colleges. [Unpublished doctoral dissertation]. University of Toronto.

House, J. S. (1981). Work stress and social support. Addison-Wesley Publishing.

Indspire. (2018). Truth and reconciliation in post-secondary settings: Student experiences. https://indspire.ca/wpcontent/uploads/2019/10/JMGD 003 IND TR REPORT FINAL V3 NOV15 V3.pdf

Ladson-Billings, G. (2014). Culturally relevant pedagogy 2.0: A.K.A the remix. Harvard Educational Review, 84(1), 74-84. https://doi.org/10.17763/ haer.84.1.p2rj131485484751

Lincoln, Y. S., \& Guba, E. G. (1985). Naturalistic inquiry. Sage.

Lundberg, C. A. (2014). Institutional support and interpersonal climate as predictors of learning for Native American students. Journal of College Student Development, 55(3), 263-277. https://doi.org/10.1353/ csd.2014.0027

McCarty, T. L., \& Lee, T. S. (2014). Critical culturally sustaining/revitalizing pedagogy and Indigenous education sovereignty. Harvard Educational Review, 84(1), 101-136. https://doi.org/10.17763/ haer.84.1.983746nl5pj34216

Office of the Registrar. (2018). Aboriginal student enrolment 2017: Prince Albert campus. [Unpublished report]. First Nations University of Canada.

Paris, D. (2012). Culturally sustaining pedagogy: A needed change in stance, terminology and practice. Educational Researcher, 41(3), 93-97. https:// www.jstor.org/stable/41477769

Patton, M. Q. (2015). Qualitative research \& evaluation methods (4th ed.). Sage.

Pidgeon, M. (2008). It takes more than good intentions: Institutional accountability and responsibility to Indigenous higher education [Unpublished doctoral dissertation]. University of British Columbia.

Pidgeon, M. (2014). Moving beyond good intentions: Indigenizing higher education in British Columbia universities through institutional responsibility and accountability. Journal of American Indian Education, 53(2), 7-28. https://www.jstor.org/stable/43610473

Pidgeon, M. (2016). More than a checklist: Meaningful Indigenous inclusion in higher education. Social Inclusion, 4(1), 77-91. https://doi.org/10.17645/ si.v4i 1.436

Ragoonaden, K., \& Mueller, L. (2017). Culturally responsive pedagogy: Indigenizing curriculum. Canadian Journal of Higher Education, 47(2), 22-46. https:/l doi.org/10.47678/cjhe.v47i2.187963

Rawana, J. S., Sieukaran, D. D., Nguyen, H. T., \& Pitawanakwat, R. (2015). Development and evaluation of a peer mentorship program for Aboriginal university students. Canadian Journal of Education, 38(2), 1-35. https://doi.org/10.2307/canajeducrevucan.38.2.08

Restoule, J. P., Mashford-Pringle, A., Chacaby, M., Smilie, C., Brunette, C., \& Russel, G. (2013). Supporting successful transitions to post-secondary education for Indigenous students: Lessons from an institutional ethnography in Ontario, Canada. International Indigenous Policy Journal, 4(4), 1-10. https://doi.org/10.18584/iipj.2013.4.4.4

Santamaría, L., \& Santamaría, A. P. (2016). Toward culturally sustaining leadership: Innovation beyond 'school improvement' promoting equity in diverse contexts. Education Sciences, 6(33), 1-8. https:/l doi.org/10.3390/educsci6040033

Savitz-Romer, M., Jager-Hyman, J., \& Coles, A. (2009). Removing roadblocks to rigor: Linking academic and social support to ensure college readiness and 
success. Pathways to College Network, Institute for Higher Education Policy. http://www.ihep.org/research/publications/removing-roadblocks-rigor-linking-academic-and-social-supports-ensure-colleg-0

Smith, N. L., \& Varghese, J. (2016). Role, impacts and implications of dedicated Aboriginal student space at a Canadian university. Journal of Student Affairs Research and Practice, 53(4), 458-469. https://doi. org/10.1080/19496591.2016.1167065

Smylie, J., Firestone, M., Cochran, L., Prince, C., Maracle, S., Morley, M., Mayo, S., Spiller, T., \& McPherson, B. (2011). Our health counts: Urban Aboriginal health database research project: Community report well living house. http://www.welllivinghouse. com/wp-content/uploads/2014/04/our-healthcounts-report-Hamilton2.pdf

Stake, R. E. (1995). The art of case study research. Sage.

Statistics Canada. (2013). Aboriginal peoples in Canada: First Nations people, Métis and Inuit, national household survey 2011. https://www12. statcan.gc.ca/nhs-enm/2011/as-sa/99-011-x/99-011x2011001-eng.cfm

Statistics Canada. (2016). Census profile, 2016 census, Prince Albert, Saskatchewan. https://www12. statcan.gc.ca/census-recensement/2016/dp-pd/prof/ details/page.cfm?B1=All\&Code1=745\&Code2=47\&Data=Count\&Geo1=CMACA\&Geo2=PR\&Lang=E\&SearchPR=01\&SearchText=Prince+Albert\&SearchType $=$ Begins $\&$ TABID $=1$

Statistics Canada. (2018). Aboriginal population profile, 2016 census. https://www12.statcan.gc.ca/census-recensement/2016/dp-pd/abpopprof/details/ page.cfm?Lang $=E \& G e 01=\& C o d e 1=\& D a t a=C o u n t \&-$ SearchText=Canada\&SearchType $=\mathrm{Be}-$ gins\&B1=All\&SEX ID=1\&AGE ID=1\&RESGEO $\underline{\mathrm{ID}=1}$

Tachine, A. R., Cabrera, N. L., \& Yellow Bird, E. (2017). Home away from home: Native American students' sense of belonging during their first year in college. The Journal of Higher Education, 88(5), 785-807. https://doi.org/10.1080/00221546.2016.1257322
Timmons, V., \& Stoicheff, P. (2016). Post-secondary education in Canada: A response to the Truth and Reconciliation Commission of Canada. Johnson Shoyama Graduate School of Public Policy. https:/l www.schoolofpublicpolicy.sk.ca/documents/research/policy-briefs/PolicyBrief-Post\%20Secondary\%20Education\%20in\%20Canada.pdf

Truth and Reconciliation Commission of Canada. (2015). Truth and reconciliation commission of Canada: Calls to action. http://trc.ca/assets/pdf/ Calls to Action English2.pdf

Universities Canada. (2015). Universities Canada principles on Indigenous education. https://www. univcan.ca/wp-content/uploads/2015/11/principles-on-indigenous-education-universities-canada-june-2015.pdf

Windchief, S., \& Joseph, D. H. (2015). The act of claiming higher education as Indigenous space: American Indian/Alaska Native examples. Diaspora, Indigenous, and Minority Education, 9(4), 267-283. https://doi.org/10.1080/15595692.2015.1048853

\section{Contact Information}

Tania Kristoff

Tania.kristoff@usask.ca 